\title{
Reliability of reported family history of myocardial infarction
}

\author{
F Kee, L Tiret, J Y Robo, V Nicaud, E McCrum, A Evans, F Cambien
}

Abstract

Objective-To assess the reliability of reported family histories of myocardial infarction.

Design-A case-control study in which reported histories of first degree relatives were validated from death certificates, general practitioners' records, and hospital notes.

Setting-Participants enrolled in the Belfast centre of the World Health Organisation's study monitoring trends and determinants in cardiovascular disease (MONICA).

Subjects-200 men who survived myocardial infarction and 200 age matched controls drawn randomly from the population.

Main outcome measures-The sensitivity, specificity, positive predictive value, and proportion of overall agreement with validated records of reported family histories of myocardial infarction in first degree relatives; odds ratios for myocardial infarction, given at least one reported relative or at least one verified relative being affected.

Results -349 of the 400 probands provided detailed family histories, reporting on 2812 first degree relatives. The overall sensitivity, specificity, and positive predictive value of reported histories were $67 \cdot 3 \%, 96 \cdot 5 \%$, and $70 \cdot 5 \%$ for cases and $68 \cdot 5 \%$, $97.7 \%$, and $73.8 \%$ for controls. The $\kappa$ coefficients were modest: 0.65 for cases and 0.68 for controls. The odds ratios for myocardial infarction, given at least one affected relative, were not substantially inflated by recall bias. Some recall bias was evident for the probands' reports of their siblings' histories of myocardial infarction, the odds ratio for a reported history being 1.67 (95\% confidence interval 1.09 to 2.57 ) and for the validated history 1.54 $(1 \cdot 01$ to $2 \cdot 37)$.

Conclusions-Although the relative risk of disease is correctly estimated, the predictive accuracy of a casual family history of myocardial infarction may limit the effectiveness of targeted screening programmes. They may, however, complement other strategies based on genetic testing.

\section{Introduction}

Currently there is debate about the most appropriate strategy for preventing coronary artery disease. One approach is to reduce the average value of a risk factor in the entire population. ${ }^{1} \mathrm{~A}$ limitation of this strategy is that traditional risk factors (such as smoking, high cholesterol concentration, and hypertension) explain little more than half of the overall variation in risk in the community. ${ }^{2}$ An alternative approach is to target for intervention those perceived to be at greatest risk. One such group are those with a family history of myocardial infarction. ${ }^{34}$ Indeed a range of genetic tests have recently become available for a variety of chronic diseases that may allow more accurate definition of such susceptible groups. ${ }^{5-7}$

Despite many attempts to disentangle the independent effects of a family history on coronary risk most have relied primarily on self reported family histories. ${ }^{8-12}$ Considerable bias can arise if unvalidated proxy information is obtained from the next of kin. ${ }^{13-15}$ Such bias could affect the estimate of risk attributable to a family history and could also limit the effectiveness of a targeted screening programme. We assessed the reliability of the self reported (first degree) family history of myocardial infarction.

\section{Subjects and methods}

The étude cas-témoin sur l'infarctus du myocarde (ECTIM) study is a case-control study of myocardial infarction, which has investigated the differences in the incidence of and mortality from coronary heart disease between four centres in France and Northern Ireland (Strasbourg, Toulouse, Lille, and Belfast) that are part of the World Health Organisation's study monitoring trends and determinants in cardiovascular disease (MONICA) ${ }^{16}$ Cases were men aged $25-64$ years who had survived for at least three months after a myocardial infarction, and controls were age matched men drawn randomly from the population. This paper relates only to the 400 probands recruited in Northern Ireland.

Each subject was interviewed at home and asked to provide details of the medical histories of first degree relatives by using terms coronary, coronary thrombosis, and heart attack, when appropriate. Family doctors of living relatives were asked to validate any known history of ischaemic heart disease whether or not reported by the proband. Hospital charts were retrieved when a history of myocardial infarction was reported. Verification of myocardial infarction by death certificate was accepted when the underlying cause corresponded to code 410 of the International Classification of Diseases, ninth revision.

The sensitivity, specificity, and predictive value of a reported family history were calculated by comparing the reported with the validated state of the relatives. We assessed the congruity between the reported and corroborated histories by using the $\kappa$ statistic, which measures the proportion of agreement beyond that expected by chance. ${ }^{17}$ Odds ratio for myocardial infarction were calculated first with uncorroborated and then with validated family histories by using logistic regression adjusted for the proband's age and size of family.

\section{Results}

A total of 174 cases and 175 controls $(87 \%$ of the original sample) provided detailed family histories. The average age of cases and controls was 54.4 years and 54.1 years, respectively. Two of the controls were being treated with drugs for hyperlipidaemia and $18 \mathrm{had}$ histories of angina. A death certificate was obtained for 753 out of 783 relatives who had died $(96 \%)$. The medical histories of 1893 out of $2029(93 \%)$ living relatives were verified from a secondary source.

The table shows the number of relatives reported as having had a myocardial infarction and the numbers confirmed. In cases the sensitivity, positive predictive value, and specificity of a reported history of infarction in these relatives was $67.3 \%, 70.5 \%$, and $96.5 \%$, respectively. These did not differ significantly from the corresponding figures for controls $(68.5 \%, 73.8 \%$, and $97.7 \%$, respectively). The overall index of agreement between reported and validated histories was modest, 


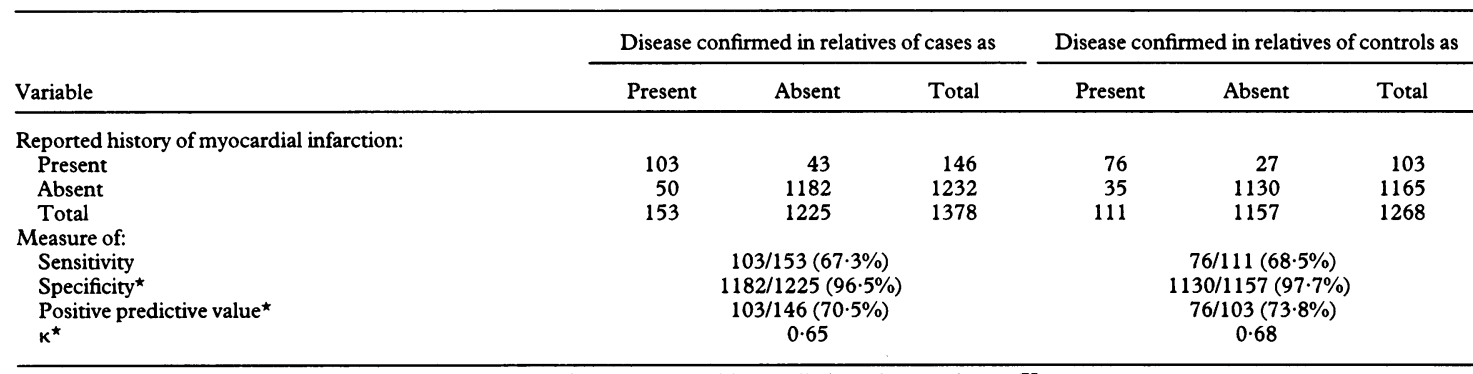

${ }^{\star} \mathrm{p}$ Values for cases $v$ controls: 0.85 (sensitivity); 0.11 (specificity); 0.68 (positive predictive value); and 0.55 (K).

with $\kappa$ coefficients of 0.65 for cases and 0.68 for controls.

A comparison of cases and controls produced odds ratios ( $95 \%$ confidence intervals) for myocardial infarction, given a reported affected relative of 1.67 (1.09 to $2.57)$ for any relative, $1.57(1.02$ to 2.42$)$ for a parent, and $1.74(1.02$ to 2.96$)$ for a sibling. Through the use of validated histories, however, these were 1.54 (1.01 to $2.37)$ for any relative, $1.64(1.06$ to 2.52$)$ for a parent, and $1.61(0.93$ to $2 \cdot 77)$ for a sibling.

\section{Discussion}

Modestly increased relative risks for a family history of chronic disease may obscure higher relative risks specific for genotypes. ${ }^{18}$ With the identification of genetic factors predisposing to myocardial infarction it will eventually be possible to have better targeted screening programmes, but genetic screening is unlikely to be considered in the whole population and should be focused on families at high risk. Few studies, however, have attempted to validate independently the accuracy of a family history of myocardial infarction. ${ }^{19-29}$ Some of these studies have provided only partial insights because of a small sample size, too loose a definition of phenotype (any coronary heart disease), corroboration of only positive reports, or verification being limited to dead or living kin (but not both). The verification possible in this study was much higher than in previous reports.

The validity of our corroboration of family histories ultimately depends on the reliability of the secondary sources themselves. Official mortality data reliably record deaths from coronary heart disease in this area, ${ }^{30}$ and the number of false positive diagnoses on death certificates is low (A E Evans, personal communication). Medical histories among living relatives were substantiated by using general practitioners' records, and when a hospital chart was also available to us we found that the general practitioners had very reliably reported the hospital diagnoses.

From an epidemiological point of view the crucial issue is the estimate of the relative risk of disease associated with a family history. Classic sources of bias are misclassification, ${ }^{31}$ which leads to an underestimate

\section{Clinical implications}

- Having a relative who has had a coronary is a risk factor for myocardial infarction

- Patients with such a family history may merit screening for other remediable risk factors

- This study found that such family histories given in the clinic or surgery will miss about a third of those at risk and will overestimate the number of relatives affected by about a third

- Prevention strategies based on interventions in high risk groups must be adequately focused of the effect, and recall bias, which tends to inflate it. In our study small differences were observed between odds ratios based on reported and verified data, indicating that neither of these biases had a substantial impact on the measurement of the effect of interest. From a clinical point of view the moderate degree of agreement between reported and verified information might be more important with respect to the effectiveness of a prevention strategy based on a high risk approach. In particular, the relatively low sensitivity indicates that a substantial proportion of subjects at risk would not be detected.

Because the predictive accuracy of the reported family history might be affected by the underlying prevalence of disease, ${ }^{32}$ our findings should be applied to other communities only with caution, particularly if those communities have a lower prevalence of myocardial infarction. Further studies are also warranted to compare accuracy of recall in men and women.

1 Rose G, Day S. The population mean predicts the number of deviant individuals. $B M F$ 1990;301:1031-4.

2 Marmot MG, Davey Smith G, Stansfield S, Patel C, North F, Head J, et al. Health inequalities among British civil servants: the Whitehall II study. Lancet 1991;337:1387-93.

3 Lauer RM. A family history of risk factors and cardiovascular diseases. Circulation 1991;84:1445-6.

4 Singer F. Risk factors for coronary artery disease: taking the family history. Am Heart f 1991;121:947-8.

5 Cambien F, Poirier O, Lecerf L, Evans AE, Cambou JP, Arveiller D, et al. Deletion polymorphism for angiotensin converting enzyme is a potent risk factor for myocardial infarction. Nature 1992;359:641-4

6 Davignon J, Gregg RE, Sing CF. Apolipoprotein E polymorphism and atherosclerosis. Arteriosclerosis 1988;8:1-21.

7 Khoury M, Beaty T, Flanders D. Epidemiologic approaches to the use of DNA markers in the search for disease susceptibility genes. Epidemiol Rev 1990;12:41-55.

8 Roncaglioni MC, Santoro L, D'Avanzo B, Negri E, Nobili A, Ledda A, et al. Role of family history in patients with myocardial infarction. Circulation 1992;85:2065-72.

9 Colditz G, Rimm E, Giovanucci E, Stampfer MJ, Rosner B, Willett W. A prospective study of parental history of myocardial infarction and coronary prospective study of parental history of myocardia.

10 Snowden CB, McNamara PM, Garrison RJ, Feinleib M, Kannel WB, Epstein FH. Predicting coronary heart disease in siblings: a multivariate assessment. FH. Predicting coronary heart dise

11 Khaw KT, Barret-Connor E. Family history of heart attack: a modifiable risk factor? Circulation 1986;74:239-44.

12 Ten Kate LP, Boman H, Daiger SP, Motulsky AG. Familial aggregation of coronary heart disease and its relation to known genetic risk factors. Am f Cardiol 1982;50:945-53.

13 Perkins K. Family history of coronary heart disease: is it an independent risk factor? Am f Epidemiol 1986;124:182-94.

14 Nelson LM, Longstreth WT, Koepsell T, van Belle G. Proxy respondents in epidemiological research. Epidemiol Rev 1990;12:71-86.

15 Hermann N. Retrospective information from questionnaires. I. Comparability of primary respondents and their next of kin. Am f Epidemiol 1985;121: of prim.

16 Parra HJ, Arveiler D, Evans A, Cambou JP, Amuoyel P, Bingham A, et al. A case control study of lipoprotein particles in two populations at contrasting risk for coronary heart disease. The ECTIM study. Arteriosclerosis and Thrombosis 1992;12:701-7.

17 Fleiss JL. Statistical methods for rates and proportions. 2nd ed. New York: Wiley, 1987.

18 Khoury M, Flanders D, Greenland S, Adams M. On the measurement of susceptibility in epidemiological studies. Am $\mathcal{F}$ Epidemiol 1989;129:183-90.

19 Rose G. Familial patterns in ischaemic heart disease. British fournal of Preventive and Social Medicine 1964;18:75-80.

20 Slack J, Evans KA. The increased risk of death from ischaemic heart disease in first degree relatives of 121 men and 96 women with ischaemic heart disease. f Med Genet 1966;3:239-57.

21 Napier JA, Metzner H, Johnson BC. Limitations of morbidity and mortality data obtained from family histories: a report from the Tecumseh community data obtained from family histories: a report

22 Olav H, Thelle DS. The Tromso heart study: risk factors for coronary heart disease related to the occurrence of myocardial infarction in first degree relatives. Am $\mathcal{F}$ Epidemiol 1977;105:192-9. 
23 Thelle DS, Forde $\mathrm{OH}$. The cardiovascular study in Finnmark county: coronary risk factors and the occurrence of myocardial infarction in first degree relatives and in subjects of different ethnic origin. Am $\mathcal{f}$ Epidemio 1979;110:708-15

24 Rissanen A. Familial occurrence of coronary heart disease: effect of age at diagnosis. Am f Cardiol 1979;44:60-6.

25 Rissanen A, Nikkala E. Identification of the high risk groups in familia coronary heart disease. Atherosclerosis 1984;53:37-46.

26 Hunt SC, Williams RR, Barlow GK. A comparison of positive family history definitions for defining risk of future disease. 7 Clin Epidemiol 1986;39: $809-21$.

27 Heller R, Kelson MC. Family history in low risk men with coronary heart disease. $\mathcal{F}$ Epidemiol Community Health 1983;37:29-3
28 Phillips AN, Shaper AG, Pocock SJ, Walker M. Parental death and the risk of heart attack. Eur Heart f 1988;9:243-51.

29 Myers R, Kiely D, Cupples A, Kannel W. Parental history is an independent risk factor for coronary artery disease: the Framingham study. Am Heart $\mathcal{f}$ 1990;120:963-9.

30 Patterson CC, McCrum EE, Matthewson Z, Evans A. Validation of two methods of long term follow up. Ulster Med $f$ 1990;59:177-82.

31 Mertens TE. Estimating the effects of misclassification. Lancet 1993;342: 418-21.

32 Cicchetti DV, Feinstein AR. High agreement but low kappa. II. Resolving the paradoxes. 7 Clin Epidemiol 1990;43:551-8.

(Accepted 22 September 1993)

\title{
Further follow up of mortality and incidence of cancer in men from the United Kingdom who participated in the United Kingdom's atmospheric nuclear weapon tests and experimental programmes
}

\author{
S C Darby, G M Kendall, T P Fell, R Doll, A A Goodill, A J Conquest, D A Jackson, R G E Haylock
}

Abstract

Objectives-To study the long term effects of participation in the United Kingdom's atmospheric nuclear weapon tests and experimental programmes and to test hypotheses generated by an earlier report, including the possibility that participation in tests caused small hazards of leukaemia and multiple myeloma.

Design-Follow up study of mortality and cancer incidence.

Subjects-21358 servicemen and civilians from the United Kingdom who participated in the tests and a control group of 22333 non-participants.

Main outcome measures-Numbers of deaths; standardised mortality ratios; relative risks of mortality from all causes and 27 types of cancer.

Results-During seven further years of follow up the numbers of deaths observed in participants were fewer than expected from national rates for all causes, all neoplasms, leukaemia, and multiple myeloma (standardised mortality ratios $0.86,0.85$, 0.57 , and 0.46 ); death rates were lower than in controls (relative risks $0.99,0.96,0.57$, and 0.57 ; $90 \%$ confidence intervals all included $1 \cdot 00$ ). In the period more than 10 years after the initial participation in tests the relative risk of death in participants compared with controls was near unity for all causes (relative risk $0.99(0.95$ to 1.04$))$ and all neoplasms $(0.95(0.87$ to 1.04$))$; it was raised for bladder cancer $(2.69(1.42$ to $5 \cdot 20))$ and reduced for cancers of the mouth, tongue, and pharynx $(0.45$ $(0.22$ to 0.93$))$ and for lung cancer $(0.85(0.73$ to $0.99)$ ). For leukaemia mortality was equal to that expected from national rates but greater than in controls for both the whole follow up period $(1.75$ $(1.01$ to 3.06$))$ and the period $2-25$ years after the tests $(3.38(1 \cdot 45$ to $8 \cdot 25))$.

Conclusion-Participation in nuclear weapon tests had no detectable effect on expectation of life or on subsequent risk of developing cancer or other fatal diseases. The excess of leukaemia in participants compared with controls seems to be principally due to a chance deficit in the controls, but the possibility that participation in the tests may have caused a small risk of leukaemia in the early years afterwards cannot be ruled out.

Harkness Laboratory,

Radcliffe Infirmary, Oxford OX2 6HE

$\mathrm{R}$ Doll, honorary consultant

Correspondence to: Dr Darby.

\section{Introduction}

A previous study of the health of men from the United Kingdom who took part in the United Kingdom's programme of atmospheric nuclear weapon tests in Australia and the Pacific Ocean during the 1950s and
1960 s showed that the total mortality and the mortality from all neoplasms combined were both almost identical in test participants and in a matched control group. ${ }^{12}$ The mortality from leukaemia and from multiple myeloma was, however, substantially higher in the test participants than in controls (though not much greater than would be expected from comparison with national data), while the mortality from the two diseases most closely related to smoking was significantly lower in the test participants than in the controls. Three hypotheses were, therefore, suggested which could be tested only by further observationsnamely, that $(a)$ test participation caused small hazards of leukaemia (excluding chronic lymphatic leukaemia) and multiple myeloma; $(b)$ test participation did not cause a detectable hazard of any other cancer or of any other disease that has an appreciable death rate; and (c) that participants smoked less than other similarly employed men. The men have now been followed up for a further seven years to see whether these hypotheses could be confirmed and to examine the long term effects of test participation. The present report presents a summary of the findings. Full details are given elsewhere. ${ }^{3}$

\section{Subjects and methods}

STUDY POPULATION

The testing programme took place at the Monte Bello Islands, Emu Field, and Maralinga Range in Australia and at Malden and Christmas Islands in the Pacific Ocean. Ministry of Defence records dating from the time of the tests were searched to identify serviemen from the United Kingdom and employees of the Atomic Weapons Establishment and the Atomic Energy Research Establishment or their preceding organisations who visited one of these locations for the tests or sampled radioactive clouds. A total of 21358 participants were identified: $6304(29 \%)$ in the Royal Navy, $5794(27 \%)$ in the army, $8444(40 \%)$ in the Royal Air Force, and $816(4 \%)$ in the civilian workforce. The men are those that were studied previously, plus a few additional participants found in archival material but excluding 1503 men with no more likelihood than members of the general public of having been exposed to radiation from the tests (usually because they had left the test locations before the first detonation).

A control group of 22.333 men who had not parof Defence archives. Controls for servicemen chosen from other servicemen who had served in tropical or subtropical areas at the time of the tests. Controls for the men in the Royal Navy and for officers 